\title{
Contemporary patterns of surgery and outcomes for aortic coarctation: An analysis of the Society of Thoracic Surgeons Congenital Heart Surgery Database
}

\author{
Ross M. Ungerleider, MD, MBA, ${ }^{a}$ Sara K. Pasquali, MD, ${ }^{\text {bc }}$ Karl F. Welke, MD, ${ }^{\mathrm{d}}$ Amelia S. Wallace, BS, ${ }^{\mathrm{c}}$ \\ Yoshio Ootaki, MD, PhD, ${ }^{\mathrm{a}}$ Michael D. Quartermain, MD, ${ }^{\mathrm{e}}$ Derek A. Williams, DO, ${ }^{\mathrm{e}}$ and \\ Jeffrey P. Jacobs, $\mathrm{MD}^{\mathrm{f}}$
}

Objective: The objective of this study was to describe characteristics and early outcomes across a large multicenter cohort undergoing coarctation or hypoplastic aortic arch repair.

\begin{abstract}
Methods: Patients undergoing coarctation or hypoplastic aortic arch repair (2006-2010) as their first cardiovascular operation in the Society of Thoracic Surgeons Congenital Heart Surgery Database were included. Group 1 patients consisted of those with coarctation or hypoplastic aortic arch without ventricular septal defect (coarctation or hypoplastic aortic arch, isolated); group 2, coarctation or hypoplastic aortic arch with ventricular septal defect (coarctation or hypoplastic aortic arch, ventricular septal defect); and group 3, coarctation or hypoplastic aortic arch with other major cardiac diagnoses (coarctation or hypoplastic aortic arch, other).
\end{abstract}

\begin{abstract}
Results: The cohort included 5025 patients (95 centers): group 1, 2705 (54\%); group 2, 840 (17\%); and group 3 , $1480(29 \%)$. Group 1 underwent coarctation or hypoplastic aortic arch repair at an older age than groups 2 and 3 (groups 1,2 , and $3,75 \%, 99 \%$, and $88 \%<1$ year old, respectively; $P<.0001$ ). The most common operative techniques for coarctation or hypoplastic aortic arch repair (group 1) were end-to-end $(33 \%)$ or extended end-to-end (56\%) anastomosis. Overall mortality was $2.4 \%$, and was $1 \%, 2.5 \%$, and $4.8 \%$ for groups 1,2 , and 3 respectively $(P<.0001)$. Ventricular septal defect management strategies for group 2 patients included ventricular septal defect closure $(\mathrm{n}=211,25 \%)$, pulmonary artery band $(\mathrm{n}=89,11 \%)$, or no intervention $(\mathrm{n}=540,64 \%)$ without significant difference in mortality $(4 \%, 1 \%, 2 \% ; P=.15)$. Postoperative complications occurred in $36 \%$ of patients overall and were more common in groups 2 and 3 . There were no occurrences of spinal cord injury (0/973).
\end{abstract}

Conclusions: In the current era, primary coarctation or hypoplastic aortic arch repair is performed predominantly in neonates and infants. Overall mortality is low, although those with concomitant defects are at risk for higher morbidity and mortality. The risk of spinal cord injury is lower than previously reported. (J Thorac Cardiovasc Surg 2013;145:150-8)

The surgical management for coarctation of the aorta has changed considerably since the first successful surgical repairs done in the mid 1940s. ${ }^{1,2}$ By the 1950s, surgical repair

From the Department of Cardiothoracic Surgery, ${ }^{a}$ Brenner Children's Hospital, Wake Forest Baptist Health, Winston Salem, NC; the Department of Pediatrics, ${ }^{b}$ Duke University School of Medicine, Durham, NC; Duke Clinical Research Institute, ${ }^{c}$ Durham, NC; Seattle Children's Hospital, ${ }^{\mathrm{d}}$ Seattle, Wash; the Division of Pediatric Cardiology, ${ }^{\mathrm{e}}$ Department of Pediatrics, Brenner Children's Hospital, Wake Forest Baptist Health, Winston Salem, NC; and The Congenital Heart Institute of Florida, ${ }^{\mathrm{f}}$ All Children's Hospital, University of South Florida College of Medicine, Saint Petersburg and Tampa, Fla

Disclosures: Dr Pasquali has received grant support from the National Heart, Lung, and Blood Institute (1K08HL103631-01). Dr Jacobs is Chair, Society of Thoracic Surgeons Congenital Heart Surgery Database Task Force. All other authors have nothing to disclose with regard to commercial support.

Read at the 38th Annual Meeting of The Western Thoracic Surgical Association, Maui, Hawaii, June 27-30, 2012.

Received for publication June 22, 2012; revisions received Aug 14, 2012; accepted for publication Sept 20, 2012; available ahead of print Oct 24, 2012.

Address for reprints: Ross M. Ungerleider, MD, MBA, Wake Forest University, Winston Salem, NC 27157 (E-mail: rungerle@wakehealth.edu).

$0022-5223 / \$ 36.00$

Copyright (c) 2013 by The American Association for Thoracic Surgery

http://dx.doi.org/10.1016/j.jtcvs.2012.09.053 was being extended to infants and, with the introduction of prostaglandins in the mid 1970s, it became possible to stabilize critically ill neonates and to offer surgical repair of aortic coarctation for patients with complex disease. Throughout the many decades since the first successful surgery, techniques have included end-to-end resection and anastomosis, ${ }^{1,2}$ subclavian flap aortoplasty, ${ }^{3}$ patch graft aortoplasty, ${ }^{4,5}$ and extended end-to-end repair. ${ }^{6-8}$ Indications and techniques for performing repair through a sternotomy have also been described, ${ }^{9}$ and this approach is now used commonly when coarctation of the aorta is associated with hypoplasia of the aortic arch. ${ }^{10}$

Prior to the availability of prostaglandins, patients receiving repair for aortic coarctation were often adolescents or young adults whose disease was found on a routine physical exam for sports or during a workup for hypertension. Children and young adults undergoing coarctation repair occasionally demonstrated some disturbing postoperative complications. $^{11}$ In 1972, Brewer and colleagues ${ }^{12}$ reviewed 12,532 coarctectomies and found 66 instances of 


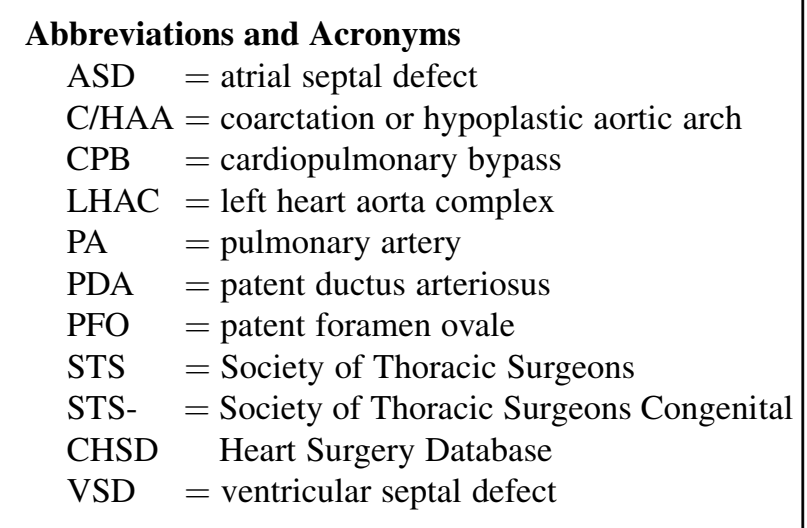

spinal cord injury, 51 of which were paraplegia, and the commonly cited risk of paraplegia remains today at their described incidence of $0.41 \%$.

The outcomes and incidence of complications for coarctation repair in our current surgical era have not been investigated. The purpose of this study is to describe characteristics and early outcomes across a large, multicenter, contemporary cohort undergoing coarctation repair.

\section{METHODS}

\section{Data Source}

The Society of Thoracic Surgeons Congenital Heart Surgery Database (STS-CHSD) is the largest pediatric heart surgery registry worldwide and currently contains information on $>240,000$ operations performed in North America since 1998. It is estimated that the database currently represents $>80 \%$ of all pediatric heart centers in the United States. ${ }^{13}$ Perioperative, operative, and outcomes data are collected on all patients coded as undergoing congenital and pediatric heart surgery at participating centers. Data quality are evaluated through intrinsic data verification (eg, identification and correction of missing/out-of-range value and inconsistencies in values across fields), and a formal process of site visits and data audits. ${ }^{14}$ The Duke Clinical Research Institute serves as the data warehouse and analytic center for all STS databases. This study was approved by the Duke University institutional review board with waiver of informed consent and by the Access and Publications Committee of the STS-CHSD.

\section{Study Population}

The study population included patients from any STS-participating center undergoing coarctation or hypoplastic aortic arch (C/HAA) repair as their first cardiovascular operation from 2006 to 2010 (patients with a history of previous cardiac surgery were excluded). We included both coarctation repair and aortic arch repair in our review because we felt they both addressed a spectrum of the same anatomic problem-important narrowing of the thoracic aorta that required surgical intervention as an initial intervention. Patients with missing data for key study variables were excluded.

\section{Data Collection}

Patient characteristics included age at surgery, gender, weight, cardiac diagnoses, any noncardiac/genetic abnormalities, and any preoperative factors as defined by the STS-CHSD. ${ }^{15}$ Operative variables included use of cardiopulmonary bypass ( $\mathrm{CPB}$; along with bypass time if applicable), type of coarctation repair, and other procedures performed at the time of C/HAA repair, including ventricular septal defect (VSD) closure or pulmonary artery (PA) banding. Outcomes included in-hospital mortality, postoperative length of stay, and postoperative complications as defined in the STS-CHSD. ${ }^{15}$

\section{Analysis}

Patient characteristics, operative variables, and postoperative outcomes were described using standard summary statistics. These variables were described overall and then examined further for 3 main subgroups undergoing C/HAA repair as described by Backer and Mavroudis ${ }^{16}$ in the International Congenital Heart Surgery Nomenclature and Database Project: group 1, isolated C/HAA; group 2, C/HAA with a VSD; and group 3, C/HAA with other cardiac diagnoses.

Group 1 patients with isolated C/HAA had no other cardiac defects aside from secundum atrial septal defect (ASD), patent foramen ovale (PFO), or patent ductus arteriosus (PDA) (C/HAA-isolated); group 2 patients with C/HAA also had a VSD but no other cardiac lesions other than ASD, PFO, PDA (C/HAA-VSD); and group 3 patients with C/HAA had complex intracardiac anatomy, including additional left-sided cardiac lesions or other forms of complex heart disease (C/HAA-other).

Characteristics and outcomes in these 3 groups were compared using the $\chi^{2}$ test and Kruskal-Wallis test. In addition, the C/HAA-VSD group was subdivided further, and outcomes were evaluated for those undergoing VSD repair at the time of C/HAA repair, those undergoing PA banding at the time of C/HAA repair, and those with a diagnosis of VSD who did not undergo any intervention at the time of $\mathrm{C} / \mathrm{HAA}$ repair. Last, the $\mathrm{C} / \mathrm{HAA}$-other group was also subdivided further into those with other left-sided lesions (mitral or aortic valve disease, etc) versus those with other major cardiac diagnoses. All analyses were performed using SAS version 9.2 (SAS Institute, Inc, Cary, NC). A $P$ value $<.05$ was considered statistically significant.

\section{RESULTS}

\section{Preoperative and Operative Variables}

The overall cohort included 5025 patients undergoing C/HAA repair from 95 centers, including 2705 (54\%) in group $1,840(17 \%)$ in group 2 , and $1480(29 \%)$ in group 3. Table 1 displays the preoperative characteristics of these groups. Patients in the C/HAA-VSD group (group 2) were more likely to undergo surgery as neonates or infants $(P<.0001)$. Patients in groups 2 and 3 had a significantly higher likelihood of having a noncardiac or genetic abnormality $(P<.0001)$, and patients in either group 2 or group 3 were more likely to be acidotic, in shock, or require mechanical ventilation at the time of presentation $(P<.0001)$.

Table 2 displays key operative variables for the overall cohort and each of the subgroups. Cardiopulmonary bypass was used more frequently during C/HAA repair for patients in groups 2 (C/HAA-VSD) and 3 (C/HAA-other).

\section{Outcomes}

Table 3 displays outcome variables for the overall cohort and for each subgroup. The mortality data are also displayed graphically in Figure 1. In-hospital mortality was $1 \%, 2.5 \%$, and $4.8 \%$ for groups 1,2 , and 3 respectively, and was significantly higher in group $2(P=.001)$ and group $3(P<.0001)$ versus group 1 .

Overall, $36 \%$ of patients had a postoperative complication of some type. The likelihood of any postoperative complication was approximately twice as high for patients in 
TABLE 1. Preoperative variables

\begin{tabular}{|c|c|c|c|c|c|}
\hline Variable & Overall & $\begin{array}{c}\text { C/HAA-isolated, } \\
\text { group } 1 \\
\end{array}$ & $\begin{array}{c}\text { C/HAA-VSD, } \\
\text { group } 2 \\
\end{array}$ & $\begin{array}{c}\text { C/HAA-other, } \\
\text { group } 3\end{array}$ & $P$ value \\
\hline $\mathrm{n}$ & 5025 & 2705 & 840 & 1480 & \\
\hline \multicolumn{6}{|l|}{ Age at surgery, $\mathrm{d}$} \\
\hline Median & 19 & 32 & 12 & 14 & $<.0001$ \\
\hline $25 \%$ & 7 & 9 & 6 & 7 & \\
\hline $75 \%$ & 110 & 365 & 29 & 69 & \\
\hline Age group, $\mathrm{n}(\%)$ & & & & & $<.0001$ \\
\hline Neonate, 0-30 d & $2947(59)$ & $1343(49.7)$ & $643(76.6)$ & $961(64.9)$ & \\
\hline Infant, $>30 \mathrm{~d}-1 \mathrm{y}$ & $1210(24)$ & $685(25.3)$ & $187(22.3)$ & $338(22.8)$ & \\
\hline Child, $>1-12$ y & $697(13.9)$ & $553(20.4)$ & $9(1)$ & $135(9.1)$ & \\
\hline Adolescent, $>12-18 \mathrm{y}$ & $127(2.5)$ & $94(3.5)$ & $1(0.1)$ & $32(2.2)$ & \\
\hline Adult, $>18$ y & $42(1)$ & $29(1)$ & $0(0)$ & $13(1)$ & \\
\hline Male/female, $\mathrm{n}$ & $60 / 40$ & $62 / 38$ & $56 / 44$ & $59 / 41$ & .01 \\
\hline Noncardiac/genetic abnormalities, n (\%) & $1072 / 4967(21.3)$ & $446 / 2675(16.5)$ & $169 / 832(20.1)$ & $457 / 1460(30.9)$ & $<.0001$ \\
\hline Any preoperative risk factor, $\mathrm{n}(\%)$ & $1580(31)$ & $656(24)$ & $346(41)$ & $578(39)$ & $<.0001$ \\
\hline Shock, n $(\%)$ & $319(6.4)$ & $126(4.7)$ & $65(7.7)$ & $128(8.7)$ & $<.0001$ \\
\hline Acidosis, n (\%) & $227(5.6)$ & $82(3.7)$ & $49(7.4)$ & $96(8.1)$ & $<.0001$ \\
\hline Mechanical ventilation, $\mathrm{n}(\%)$ & $914(18.2)$ & $356(13.2)$ & $213(25.4)$ & $345(23.3)$ & $<.0001$ \\
\hline
\end{tabular}

C/HAA, Coarctation or hypoplastic aortic arch; VSD, ventricular septal defect.

groups 2 or 3 compared with group $1(P<.0001)$. Notably, the incidence of acidosis, cardiac arrest, chylothorax, unplanned cardiac reoperation, and the need for prolonged mechanical ventilator support was higher in groups 2 and 3. Group 3 patients had the highest likelihood of unplanned readmission within 30 days. Of note was the absence of spinal cord injury in any group for the 973 total operations performed since the data field was added to the STS-CHSD in 2010.

\section{Subgroup Analysis}

Group 1. Of the 2705 patients in group 1 (C/HAA-isolated), 2474 (91\%) underwent coarctation repair as their primary procedure and $231(9 \%)$ underwent aortic arch repair. The STS-CHSD does not contain precise or strict anatomic or physiologic criteria to guide coding of coarctation versus aortic arch repair, and this choice is left to the discretion of the surgeon or coding team. For the 2474 patients in group 1 coded as undergoing coarctation repair, the STS-CHSD also specifies further the type of repair used. The vast majority $(89.1 \%)$ of these patients underwent end-to-end (or extended end-to-end) repairs. All other repair types accounted for the remaining $10.9 \%$ of operations (Table 4). Of the 2474 group 1 patients coded as undergoing coarctation repair, in-hospital mortality was not significantly different for those who underwent coarctation repair with the use of CPB $(2 / 156,1.3 \%)$ versus without CPB (18/2318, 0.8\%; $P=.5$ ). For the 231 group 1 patients coded as undergoing aortic arch repair, in-hospital mortality was also not statistically different for those who underwent aortic arch repair with $\mathrm{CPB}(5 / 210,2 \%)$ versus without $\mathrm{CPB}(2 / 21,10 \% ; P=.7)$. Group 2. For the 840 patients who underwent C/HAAVSD, $540(64 \%)$ were coded as undergoing coarctation repair as their primary procedure and $300(36 \%)$ were coded as undergoing aortic arch repair. Ventricular septal defect management fell into 1 of 3 strategies: (1) concurrent VSD repair, (2) PA banding, and (3) no intervention for the VSD. Table 5 displays patient outcomes separated by each VSD management strategy. The majority of the patients did not have their VSD closed at the time of C/HAA repair. In-hospital mortality is low and not statistically different for any strategy.

Groups 1 and 2. For the 3014 patients in groups 1 and 2 who were coded as having coarctation repair (as opposed to aortic arch repair) as their primary procedure, $2474 \mathrm{did}$ not have a VSD $(82 \%)$ and $540(16 \%)$ had a VSD. For the 531 patients who were coded as having aortic arch repair (as opposed to coarctation repair), 231 (44\%) had no VSD

TABLE 2. Operative variables

\begin{tabular}{lccccc}
\hline \multicolumn{1}{c}{ Variable } & Overall & C/HAA-isolated, group 1 & C/HAA-VSD, group 2 & C/HAA-other, group 3 & $\boldsymbol{P}$ value \\
\hline $\mathrm{n}$ & 5025 & 2705 & 840 & 1480 & \\
$\mathrm{PA}$ band, yes; $\mathrm{n}(\%)$ & $288(5.8)$ & $0(0)$ & $89(10.6)$ & $199(13.5)$ \\
$\mathrm{CPB}$, yes; $\mathrm{n}(\%)$ & $1436(28.6)$ & $366(13.5)$ & $494(58.8)$ & $576(38.9)$ \\
$\mathrm{CPB}$ time, min; mean \pm SD & $117.9 \pm 59.3$ & $98.6 \pm 62$ & $127.4 \pm 53.6$ & $<.0001$ \\
\hline
\end{tabular}

$C / H A A$, Coarctation or hypoplastic aortic arch; $V S D$, ventricular septal defect; $P A$, pulmonary artery aortoplasty; $C P B$, cardiopulmonary bypass; $S D$, standard deviation. 
TABLE 3. Outcome variables

\begin{tabular}{|c|c|c|c|c|c|}
\hline Variable & Overall & $\begin{array}{c}\text { C/HAA-isolated, } \\
\text { group } 1\end{array}$ & $\begin{array}{c}\text { C/HAA-VSD, } \\
\text { group } 2\end{array}$ & $\begin{array}{c}\text { C/HAA-other, } \\
\text { group } 3\end{array}$ & $P$ value \\
\hline $\mathrm{n}$ & 5025 & 2705 & 840 & 1480 & \\
\hline In-hospital mortality, $\mathrm{n} / \mathrm{N}(\%)$ & $119 / 5025(2.4)$ & $27 / 2705(1)$ & $21 / 840(2.5)$ & $71 / 1480(4.8)$ & $<.0001$ \\
\hline LOS, $\mathrm{d} ;$ mean $\pm \mathrm{SD}$ (median) & $14 \pm 22(7)$ & $9.7 \pm 16.2(5)$ & $19.7 \pm 24.3(11)$ & $18.6 \pm 27.6(9)$ & $<.0001$ \\
\hline Any complication, $\mathrm{n} / \mathrm{N}(\%)$ & $1816 / 5025(36)$ & $666 / 2705(24.6)$ & $463 / 840(55.1)$ & $687 / 1480(46.4)$ & $<.0001$ \\
\hline Acidosis, $\mathrm{n} / \mathrm{N}(\%)^{*}$ & $81 / 4052(2)$ & $21 / 2206(1)$ & $12 / 663(1.8)$ & $48 / 1183(4.1)$ & $<.0001$ \\
\hline Cardiac arrest, n/N (\%) & $62 / 5025(1.2)$ & $11 / 2750(0.4)$ & $19 / 840(2.3)$ & $32 / 1480(2.2)$ & $<.0001$ \\
\hline Chylothorax, n/N (\%) & $165 / 5025(3.3)$ & $56 / 2705(2.1)$ & $35 / 840(4.2)$ & $74 / 1480(5)$ & $<.0001$ \\
\hline PERD, n/N (\%) & $98 / 5025(2)$ & $36 / 2705(1.3)$ & $25 / 840(3)$ & $37 / 1480(2.5)$ & .002 \\
\hline RLN injury, n/N (\%) & $176 / 5025(3.5)$ & $42 / 2705(1.6)$ & $76 / 840(9)$ & $58 / 1480(3.9)$ & $<.0001$ \\
\hline Phrenic nerve/paralyzed diaphragm & $47 / 5025(0.9)$ & $10 / 2705(0.4)$ & $12 / 840(1.4)$ & $25 / 1480(1.7)$ & $<.0001$ \\
\hline Unplanned cardiac reoperation, $\mathrm{n} / \mathrm{N}(\%) \dagger$ & $33 / 973(3.4)$ & $7 / 479(1.4)$ & 9/177 (5.1) & 17/297 (5.7) & .002 \\
\hline Unplanned readmission within $30 \mathrm{~d}, \mathrm{n} / \mathrm{N}(\%) \dagger$ & $36 / 973(3.7)$ & $12 / 499(2.4)$ & $5 / 177(2.8)$ & $19 / 297(6.4)$ & .01 \\
\hline Spinal cord injury, $\mathrm{n} / \mathrm{N}(\%) \dagger$ & 0/973 (0) & $0 / 499(0)$ & $0 / 177(0)$ & 0/297 (0) & NA \\
\hline Mechanical ventilator support, $\mathrm{n} / \mathrm{N}(\%)$ & $253 / 5025(5)$ & $64 / 2705(2.4)$ & $57 / 840(6.8)$ & $132 / 1480(8.9)$ & $<.0001$ \\
\hline
\end{tabular}

and $300(56 \%)$ had a VSD. In the group without a VSD, mortality was higher in those undergoing aortic arch repair $(7 / 231,3 \%)$ versus those undergoing coarctation repair (20/2474, $0.8 \% ; P=.001)$. A similar relationship was seen in patients with a VSD; mortality was higher in those undergoing aortic arch repair (12/300, 4\%) compared with those undergoing coarctation repair $(9 / 540,1.7 \% ; P=.04)$. However, these data should be interpreted with certain limitations in mind, including the absence of precise anatomic or physiologic criteria in the STS-CHSD to guide coding of patients as either coarctation versus aortic arch repair, and the lack of adjustment for potentially important hemodynamic and/or anatomic variables not collected in the STS-CHSD.

Group 3. For the 1480 patients in the C/HAA-other group, $546(37 \%)$ had, primarily, defects of the left heart aorta

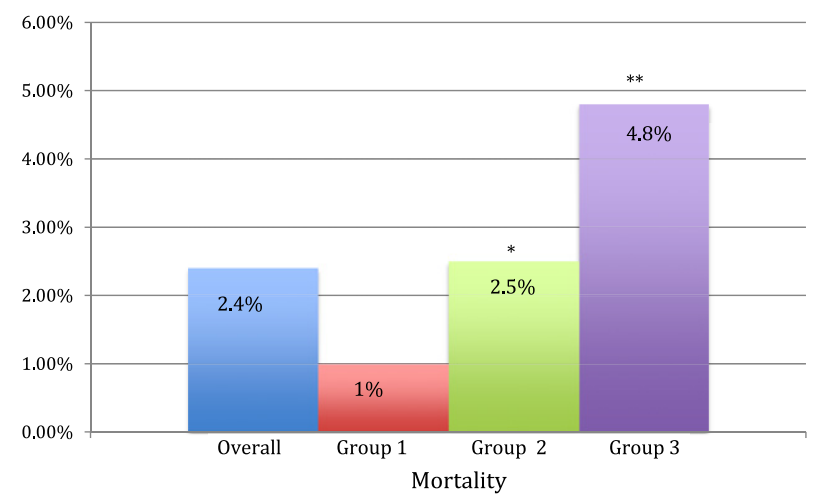

FIGURE 1. Mortality for C/HAA-isolated (group 1), C/HAA-VSD (group 2), and C/HAA-other major cardiac defects (group 3) compared with the overall cohort of 5025 patients. C/HAA, Coarctation or hypoplastic aortic arch; $V S D$, ventricular septal defect. $* P=.001$ compared with group 1. $* * P<.0001$ compared with group 1 . complex (LHAC), including Shone's syndrome. ${ }^{17}$ These defects included aortic stenosis (subvalvar, valvar, and supravalvar) and mitral stenosis (subvalvar, valvar and supravalvar), as well as a diagnosis of Shone's syndrome. The remaining 933 patients $(63 \%)$ in this group had a variety of other complex cardiac diagnoses, including atrioventricular septal defects (complete and partial), transposition of the great arteries/VSD, single ventricle (heterotaxy, unbalanced atrioventricular septal defects, double-inlet left ventricle, tricuspid atresia), double-outlet right ventricle, total anomalous pulmonary venous connection, and numerous other anomalies. Table 6 displays characteristics and outcomes for these 2 subsets. Patients in the LHAC subgroup were less likely to have noncardiac/genetic abnormalities. The LHAC subgroup also had in-hospital mortality that was significantly lower $(8 / 546,1.5 \%)$ than the subgroup with other major cardiac diagnoses $(63 / 534$, $6.8 \% ; P<.0001$; Figure 2).

\section{DISCUSSION}

This study reports the largest review of surgical repair for C/HAA in the literature to date. Our review demonstrates that patients who present in the current era for initial

TABLE 4. Frequency of coarctation repair techniques for 2474 patients in group 1 coded as undergoing coarctation repair

\begin{tabular}{lc}
\hline \multicolumn{1}{c}{ Repair technique } & Frequency, n/N (\%) \\
\hline End-to-end anastomosis & $820 / 2474(33.1)$ \\
Extended end-to-end anastomosis & $1385 / 2474(56.0)$ \\
Subclavian flap repair & $85 / 2474(3.4)$ \\
Patch aortoplasty & $104 / 2474(4.2)$ \\
Interposition graft & $70 / 2474(2.8)$ \\
Other & $10 / 2474(0.4)$ \\
\hline
\end{tabular}


TABLE 5. VSD management strategy (group 2 patients)

\begin{tabular}{|c|c|c|c|c|c|}
\hline Strategy & n $(\%)$ & $\begin{array}{c}\text { Patients in each repair } \\
\text { strategy }<1 \text { y old, } \%\end{array}$ & $\begin{array}{c}\text { CPB used for C/HAA } \\
\text { surgery, yes, n (\%) }\end{array}$ & Mortality, n (\%)* & LOS, d; median \\
\hline VSD repaired & $211(25)$ & 100 & $207(98) \dagger$ & $9(4)$ & 13 \\
\hline PA band & $89(11)$ & 99 & $23(26)$ & $1(1)$ & 13 \\
\hline No intervention for VSD & $540(64)$ & 98 & $264(49)$ & $11(2)$ & 10 \\
\hline
\end{tabular}

$\overline{C P B}$, Cardiopulmonary bypass; $C / H A A$, coarctation or hypoplastic aortic arch; $L O S$, length of stay; $V S D$, ventricular septal defect; $P A$, pulmonary artery. $* P=.15$ between groups. $\dagger$ Although it would seem that $100 \%$ of patients undergoing VSD repair should have CPB, 4 patients did not. We do not know from the database whether this represents a coding error or whether these patients had VSD closure off pump.

C/HAA surgery are frequently young (often $<1$ year of age) and can be critically ill (with a high likelihood of preoperative risk factors, especially when the C/HAA is associated with a VSD or other major cardiac diagnosis). Despite this, in-hospital mortality is low, particularly when the C/HAA is not associated with a VSD or other major cardiac defects. Our study is also the first to report the incidence of major postoperative complications from a large, multiinstitutional cohort.

Resection with end-to-end anastomosis, either without or with extension, is by far the most commonly used technique for repair of isolated coarctation (group 1 patients in our study). Patch aortoplasty, either with a prosthetic patch or a subclavian flap, is used less frequently, although prosthetic patch aortoplasty may be useful for older patients. ${ }^{18}$ Interposition grafts likely have limited, if any, role in neonatal or infant surgery and may be used more commonly in older patients.

The use of CPB to repair isolated coarctation was not associated with significantly increased mortality risk in our study.

Although our data illustrate that the preponderance of patients who currently present for primary surgical repair of C/HAA are young, $10 \%$ to $25 \%$ of C/HAA does present during childhood or adolescence, particularly when the defect is not associated with a VSD or with another major cardiac defect. Because the STS-CHSD is a surgerybased database, we do not know the number of patients who receive catheter-based interventions (eg, angioplasty or stenting) for coarctation treatment, but this likely has an effect on the number of patients presenting for surgical treatment in the older age groups. It may be possible to learn more about overall treatment for disease (as opposed to just surgical treatment for disease) and even about long-term outcomes by linking various databases to the STS-CHSD. ${ }^{19}$

Unlike an earlier, single-institution report by Conte and associates, ${ }^{10}$ the addition of a VSD to the diagnosis (group 2 patients in our study) increases significantly the mortality risk of C/HAA repair by approximately 2 times. However, this group of often-critically ill patients still has a very favorable prognosis with an overall low mortality rate. In the group of patients with $\mathrm{C} / \mathrm{HAA}-\mathrm{VSD}$, the management strategy for the VSD did not seem to influence early outcome significantly. However, each of these patients likely had different anatomic and physiologic manifestations of VSD, and the management strategies selected were likely influenced by these factors as well as by institutional or individual surgeon preferences. Therefore, it is not possible to claim from this review of the STS-CHSD that one strategy is superior to another or, in fact, that they are all indeed equal. There remains an important role for surgical experience and judgment in determining which strategy to use. Quaegebeur and colleagues ${ }^{17}$ suggested that when a VSD is present, PA banding is safer than 1-stage repair, but others during a similar time frame, ${ }^{10}$ as well as more recent reports in the literature, have challenged the validity and practicality of this approach. ${ }^{20,21}$ Because the STS-CHSD only tracks outcomes through hospitalization (and 30 days if the patient is discharged prior to 30 days following surgery), we do not know the mortality associated with the second stage, as well as the interstage, for patients initially managed with a PA band or even with deferred (eg, no) VSD intervention. As a result, our analysis cannot compare the ultimate outcome for VSD management strategies in patients with C/HAA. In their review published in 1995, Conte and associates ${ }^{10}$ observed that $39 \%$ of VSDs associated with coarctation closed spontaneously. Recent

TABLE 6. Group 3 by subgroup (LHAC/Shone's syndrome and other major cardiac defects)

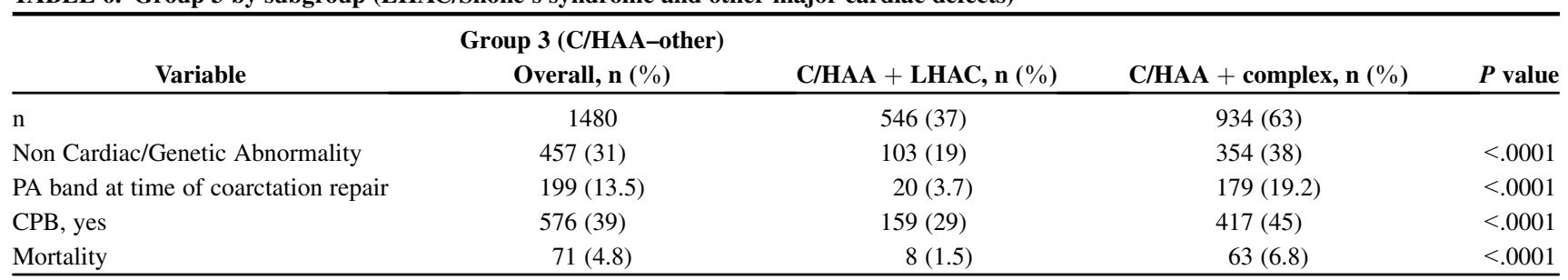

$C / H A A$, Coarctation or hypoplastic aortic arch; $L H A C$, left heart aorta complex; $P A$, pulmonary artery; $C P B$, cardiopulmonary bypass. 


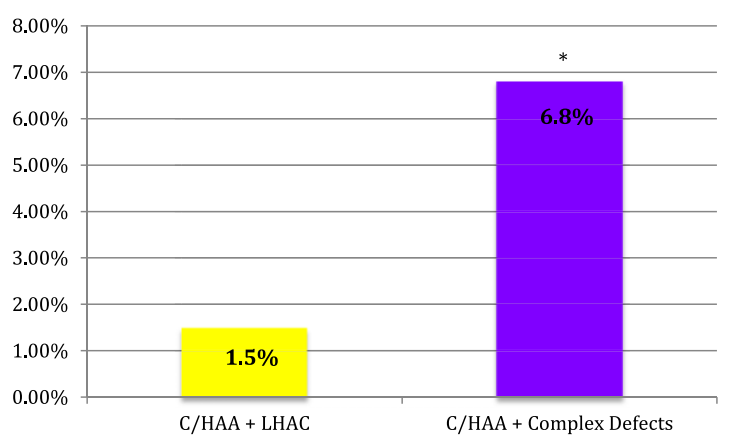

$\mathrm{C} / \mathrm{HAA}+\mathrm{LHAC}=\mathrm{C} / \mathrm{HAA}+$ left heart aorta complex disease (Shone's syndrome)

$\mathrm{C} / \mathrm{HAA}+$ Complex Defects $=\mathrm{C} / \mathrm{HAA}+$ other complex defects (aside from LHAC)

FIGURE 2. Mortality for group 3 patients (C/HAA-other) separated by whether they had C/HAA with LHAC (Shone's syndrome; C/HAA + LHAC) defects versus C/HAA with other complex defects aside from LHAC (C/HAA + Complex Defects). C/HAA, Coarctation or hypoplastic aortic arch; LHAC, left heart aorta complex. $* P<.0001$ compared with C/HAA + LHAC cohort.

modifications made to the STS-CHSD, including the addition of unique patient identifiers and detailed documentation of prior operations, will facilitate using the STS-CHSD to perform this type of analysis in the future.

Recently reported outcomes for patients undergoing repair of C/HAA have come primarily from singleinstitution series, often intended to describe the virtues of a certain surgical technique or repair strategy. ${ }^{8,20-26}$ Two multi-institutional reviews have appeared in the cardiac surgery literature during the past 18 years. In 1994, a Congenital Heart Surgeon's Society multi-institutional study was reported by Quaegebeur and colleagues. ${ }^{17}$ They described survival for 322 neonates with coarctation, 169 without, and 153 with a VSD. Unlike our current study, they excluded from analysis 109 patients with other major cardiac defects. Nonrisk-adjusted 1-month mortality was $7 \%$ and was higher for patients with a VSD. Neonates with other levels of LHAC obstruction had significantly higher mortality both at 1 month and at 24 months of follow-up. Survival was also influenced negatively by the need to extend the coarctation repair proximal to the left common carotid artery, regardless of the operative technique used. (Unfortunately, the effect of this variable on outcome in our series could not be evaluated from the data available in the STSCHSD). These outcomes were produced by Congenital Heart Surgeon's Society member institutions and are therefore likely to represent the best achievable outcomes for the time. ${ }^{27}$ In 2008, Curzon and colleagues ${ }^{28}$ reviewed outcomes in the STS-CHSD for 594 infants up to 90 days of age at the time of surgery for C/HAA. Overall, the discharge mortality was $3.5 \%$. However, the discharge mortality for low-weight infants was $7.1 \%$ compared with $2.7 \%$ for infants with weight $>2.5 \mathrm{~kg}$ and up to $4 \mathrm{~kg}$ at the time of repair. Their study was not designed to evaluate the variables in C/HAA repair (other than weight) that contribute to outcome and was not intended to provide a comprehensive analysis of C/HAA repair. In our current study, we have devised subgroups of patients for analysis by important anatomic distinctions such as the presence of a VSD or other major cardiac anomalies, because these are common accompanying issues in planning surgical management for C/HAA.

In our current study, we included patients whose C/HAA existed in association with other major cardiac defects so that the importance of having another major cardiac defect in association with C/HAA could be better understood in contrast to patients with more isolated disease of the aortic arch. Not surprisingly, when other major cardiac defects (aside from or in addition to a VSD) are associated with C/HAA, there is an increased risk for inhospital mortality and postoperative complications. Patients with C/HAA and obstructive defects of the LHAC (Shone's syndrome) have significantly lower in-hospital mortality than patients with C/HAA and other major cardiac diagnoses.

This article is the first to describe an expected incidence of major postoperative complications from a large, multiinstitutional data set. The presence of chylothorax (and/or pleural effusion requiring drainage) was low, but doubled when coarctation repair was performed in patients with VSDs or other major cardiac defects. Although the reported incidence of recurrent laryngeal nerve injury ranges from $1.6 \%$ (C/HAA-isolated) to $9 \%$ (C/HAA-VSD), the true incidence is likely higher because it is doubtful whether all the patients reported to the STS-CHSD had a direct examination to assess vocal cord function, in the absence of postoperative symptoms of aspiration or aphonia. Of particular note is the high likelihood of unplanned hospital readmission for patients having C/HAA repair with associated other cardiac diagnoses, suggesting that this is a group of patients who would benefit from careful and timely postdischarge surveillance.

The incidence of spinal cord injury is low- $0 \%$ in this series for 973 patients in the STS-CHSD since 2010 when a data field for spinal cord injury was added. Spinal cord injury has been reported in patients receiving coarctation surgery who also have hyperthermia at the time of surgery, ${ }^{29}$ as well as in patients with an aberrant right subclavian artery, ${ }^{30,31}$ but there were no patients in this large series with confirmed spinal cord injury. This low incidence is below the expected incidence of $0.41 \%$ (which would predict 3 to 4 cases for this series) reported by Brewer and colleagues, ${ }^{12}$ and suggests that the incidence, despite anecdotal reports,${ }^{31}$ is very low in the population of patients who currently present for surgery. This low incidence, in close to 1000 patients, also implies that a sample size needed to demonstrate efficacy for techniques designed to reduce the risk of this complication ${ }^{22,24,31}$ would need to be much larger than what is generally produced by 
a single center, and randomization into various treatment strategies may not be able to be powered sufficiently to address this issue. Further follow-up in the STS-CHSD over several more years may provide a more accurate, true incidence for this dreaded complication. From our review, we can simply state that the modern-day incidence of spinal cord injury following C/HAA repair is reassuringly low.

We combined the patients coded for undergoing coarctation repair and hypoplastic aortic arch repair because we felt that these 2 primary surgical procedures addressed a spectrum of the same entity-important narrowing of the aorta (diffuse or discrete) - and could not be reasonably separated because they were not adequately differentiated by the current coding criteria of the STS-CHSD. Although we caution that detailed analysis of aortic arch repair versus coarctation repair is subject to ambiguity inherent to the current STS-CHSD coding process, the data are still useful because they represent how individual surgeons perceived the repairs they were performing, and it will be important to know how these data compare with more anatomically directed coding in the future.

As in any review of STS-CHSD information, this study has important limitations. We are aggregating what seem to be similar patients but there is always the possibility of coding errors or inclusion/exclusion errors inherent to our categorizing. Nevertheless, the numbers are large enough to remove any important deficiencies. It is believable that a VSD adds to the risk and that other major cardiac defects create an even higher-risk population. Although there are individual reports that suggest high risk patients can receive coarctation or arch repair with limited risk,,$^{8,23,26}$ the numbers of patients in this review provide enough "power" to validate that while the risk of some additional lesions (even a VSD) may be small, they still create a significant effect on outcome. We would conclude that risk is individual, but can be increased by small size, ${ }^{28}$ the presence of a VSD, and other cardiac lesions (especially if they are outside the spectrum of Shone's syndrome, or LHAC).

\section{Study Limitations}

Our review is time limited and lacks longer term patient follow-up to enable conclusions to be tested against longterm outcomes. We also cannot measure the recurrence rate for coarctation and how it relates to surgical technique. If the anatomy of a coarctation, or hypoplastic aortic arch, has an influence on outcome, it is currently not definable by the data in the STS-CHSD. In the future, we would recommend that the STS-CHSD incorporate anatomic descriptors for coding coarctation repair versus aortic arch repair. Extension of the repair proximal to the left common carotid artery may be a good anatomic distinction between aortic arch repair (repair extends proximal to left common carotid artery) versus coarctation repair (repair can extend to, but not proximal to, the left common carotid artery). ${ }^{10,17,32}$ This type of coding distinction can help us understand further the results of our treatment for disease of the aortic arch.

\section{CONCLUSIONS}

Coarctation, or hypoplastic aortic arch, is a surgical disease of neonates and infants, especially when it is associated with a VSD or other major cardiac defects. When coarctation or hypoplastic aortic arch presents with only a secundum ASD, PFO, or PDA, excellent surgical outcomes can be expected. The use of CPB for coarctation repair is not associated with a significantly increased mortality risk. The presence of a VSD increases the risk for in-hospital mortality from C/HAA repair. However, the early survival for this group of patients is still excellent. The presence of other major cardiac defects (in addition to or aside from a VSD) along with C/HAA is associated with significantly higher in-hospital mortality and postoperative complications. The incidence of spinal cord injury was $0 \%$ in this large series. Future enhancements to the STS-CHSD coding criteria for coarctation and aortic arch repair can help us evaluate our treatment strategies further for disease of the aortic arch.

\section{References}

1. Crafoord C, Nylin G. Congenital coarctation of the aorta and its surgical treatment. J Thorac Surg. 1945;14:347.

2. Gross RE. Surgical correction for coarctation of the aorta. Surgery. 1945;18: 673-8.

3. Waldhausen JA, Nahrwold DL. Repair of coarctation of the aorta with a subclavian flap. J Thorac Cardiovasc Surg. 1966;51:532-3.

4. Reul GJ Jr, Kabbani SS, Sandiford FM, Wukasch DC, Cooley DA. Repair of coarctation of the thoracic aorta by patch graft aortoplasty. $J$ Thorac Cardiovasc Surg. 1974;68:696-704.

5. Yee ES, Turley K, Soifer S, Ebert PA. Synthetic patch aortoplasty: a simplified approach for coarctation in repairs during early infancy and thereafter. Am J Surg. 1984;148:240-3.

6. Amato JJ, Rheinlander HF, Cleveland RJ. A method of enlarging the distal transverse arch in infants with hypoplasia and coarctation of the aorta. Ann Thorac Surg. 1977;23:261-3.

7. Elliott MJ. Coarctation of the aorta with arch hypoplasia: improvements on a new technique. Ann Thorac Surg. 1987;44:321-3.

8. van Heurn LWE, Wong CM, Spiegelhalter DJ, Sorensen K, de Leval MR, Stark J, et al. Surgical treatment of aortic coarctation in infants younger than three months: 1985 to 1990: success of extended end-to-end arch aortoplasty. J Thorac Cardiovasc Surg. 1994;107:74-86.

9. Ungerleider RM, Ebert PA. Indications and techniques for midline approach to aortic coarctation in infants and children. Ann Thorac Surg. 1987;44:517-22.

10. Conte S, Lacour-Gayet F, Serraf A, Sousa-Uva M, Bruniaux J, Touchot A, et al. Surgical management of neonatal coarctation. J Thorac Cardiovasc Surg. 1995; 109:663-75.

11. Sealy WC, Harris JS, Young WG Jr, Calloway HA Jr. Paradoxical hypertension following resection of coarctation of the aorta. Surgery. 1957;42:135-47.

12. Brewer LA III, Fosburg RG, Mulder GA, Verska JJ. Spinal cord complications following surgery for coarctation of the aorta. J Thorac Cardiovasc Surg. 1972;64:368-81.

13. Jacobs ML, Daniel M, Mavroudis C, Morales DLS, Jacobs JP, Fraser CD, et al. Report of the 2010 Society of Thoracic Surgeons Congenital Heart Surgery Practice and Manpower Survey. Ann Thorac Surg. 2011;92:762-9.

14. Clarke DR, Breen LS, Jacobs ML, Franklin RC, Tobota Z, Maruszewski B, et al. Verification of data in congenital cardiac surgery. Cardiol Young. 2008;18:177-87. 
15. The Society of Thoracic Surgeons. STS Congenital Heart Surgery Database. Available at: http://www.STS.org/sts-national-database/database-managers/ congenital-heart-surgery-database. Accessed October 10, 2012.

16. Backer CL, Mavroudis C. Congenital Heart Surgery Nomenclature and Database Project: patent ductus arteriosus, coarctation of the aorta, and interrupted aortic arch. Ann Thorac Surg. 2000;69(suppl 1):S298-307.

17. Quaegebeur JM, Jonas RA, Weinberg AD, Blackstone EH, Kirklin JW. Outcomes in seriously ill neonates with coarctation of the aorta: a multiinstitutional study. J Thorac Cardiovasc Surg. 1994;108:841-54.

18. Backer CL, Paape K, Zales VR, Weigel TJ, Mavroudis C. Coarctation of the aorta: repair with polytetrafluoroethylene patch aortoplasty. Circulation. 1995; 92:II132-6.

19. Pasquali SK, Jacobs JP, Shook GJ, O’Brien SM, Hall M, Jacobs ML, et al. Linking clinical registry data with administrative data using indirect identifiers: implementation and validation in congenital heart surgery population. Am Heart J. 2010;160:1099-104.

20. Kanter KR, Mahle WT, Kogon BE, Kirshbom PM. What is the optimal management of infants with coarctation and ventricular septal defect? Ann Thorac Surg. 2007;84:612-8

21. Walters HL, Ionan CE, Thomas RL, Delius RE. Single-stage versus 2-stage repair of coarctation of the aorta with ventricular septal defect. $J$ Thorac Cardiovasc Surg. 2008;135:754-61.

22. Backer CL, Steward RD, Kelle AM, Mavroudis C. Use of partial cardiopulmonary bypass for coarctation repair through a left thoracotomy in children without collaterals. Ann Thorac Surg. 2006;82:964-72.

23. Burch PT, Cowley CG, Holubkov R, Null D, Lambert LM, Kouretas PC, et al. Coarctation repair in neonates and young infants: is small size or low weight still a risk factor? J Thorac Cardiovasc Surg. 2009;138:547-52.

24. Fiore AC, Ruzmetov M, Johnson RG, Rodefeld MD, Rieger K, Turrentine MW, et al. Selective use of left heart bypass for aortic coarctation. Ann Thorac Surg. 2010;89:851-7.

25. Kaushal S, Backer CL, Patel JN, Patel SK, Walker BL, Weigel TJ, et al. Coarctation of the aorta: midterm outcomes of resection with extended end-to-end anastomosis. Ann Thorac Surg. 2009;88:1932-8.

26. McGuinness JG, Elhassan Y, Lee SY, Nolke L, Oslizlok P, Walsh K, et al. Do high-risk infants have a poorer outcome from primary repair of coarctation? Analysis of 192 infants over 20 years. Ann Thorac Surg. 2010;90: 2023-7.

27. Welke KF, Shen I, Ungerleider RM. Current assessment of mortality rates in congenital heart surgery. Ann Thorac Surg. 2006;82:164-70.

28. Curzon CL, Milford-Beland S, Li JS, O'Brien SM, Jacobs JP, Jacobs ML, et al. Cardiac surgery in infants with low birth weight is associated with increased mortality: analysis of the Society of Thoracic Surgeons Congenital Heart Database. J Thorac Cardiovasc Surg. 2008;135:546-51

29. Crawford FAJ, Sade RM. Spinal cord injury associated with hyperthermia during aortic coarctation repair. J Thorac Cardiovasc Surg. 1984;87:616-8.

30. Lerberg DB, Hardesty RL, Siewers RD, Zuberbuhler JR, Bahnson HT. Coarctation of the aorta in infants and children: 25 years of experience. Ann Thorac Surg. 1982;33:159-70.

31. Setty SP, Brizard CP, d'Udekem Y. Partial cardiopulmonary bypass in infants with coarctation and anomalous right subclavian arteries. Ann Thorac Surg. 2007;84:715 [letter].

32. Wright GE, Nowak CA, Goldberg CS, Ohye RG, Bove EL, Rocchini AP. Extended resection and end-to-end anastomosis for aortic coarctation in infants: results of a tailored surgical approach. Ann Thorac Surg. 2005;80:1453-9.

\section{Discussion}

Dr Gordon A Cohen (Seattle, Wash). Dr Ungerleider, I would like to congratulate you and your coauthors for this excellent work and I want to thank you, actually, for doing it because I think it is a meaningful study in that nothing has been published with contemporary results on repair of aortic coarctation in quite awhile, and so I really think that this adds to the literature.

I have a series of questions. I will break them into 4 general themes and I will address all 4 themes now, but if you need me to repeat any of them just let me know.
First, how does this information influence our practice moving forward? Should we make any changes in how we practice and should we make any changes in how we counsel families about the surgical risk?

Second, what is the data quality, what are the limitations of the data, and how are the data limited by combining coarctation and hypoplastic aortic arch into a single group? Does this confuse the message of your study?

Third, we often think of coarctation repair as a straightforward operation with a short hospital stay. These data demonstrated a $25 \%$ incidence of complication for coarctation and the hypoplastic aortic arch group, and even higher for the other 2 with an overall $36 \%$ incidence of complications. Should we be adjusting our own expectations as well as those of the families for these operations? How could we use this information to reduce complication rates?

And last, I was actually surprised to see the large percentage of patients with these diagnoses who are being operated on outside of the neonatal period. Can you speculate as to why? Interestingly, I went to the database at Seattle Children's since July 2006 and looked up our own experience, because I thought it was different than what we actually do, and in fact found almost identical numbers; so can you speculate as to why that is the case?

Dr Ungerleider. Thank you, Gordon, not only for your questions but for your friendship over the years.

You first question was: How is this going to influence our practice? I do not know whether it will influence our practice or whether it should, but it certainly should help us understand our practice. We have a lot of data now that are collected that can give us information that we can relate to our families or to our colleagues about expectations. It also shows us a little bit about how we want to modify the database in the future to answer questions that we just simply cannot answer here, like recurrence rates or what happens from VSD management strategies, so we have some limitations with what we can say with the STS database the way it is currently constructed.

You asked about data quality-Do we confuse the issue by including hypoplastic aortic arch patients with coarctation patients?-and I hope we did not. We spent a lot of time thinking about this and we just did not know how to separate patients having aortic arch repair from patients having coarctation repair, because when patients have important narrowing of the aortic arch, some people may call that an aortic arch repair and some people a coarctation repair, and until we insert into the STS-CHSD some kind of anatomic or physiologic descriptor that will guide the coding of arch repair versus coarctation repair-and we would recommend that perhaps that be repair that extends proximal to the left common carotid artery - until we have that, we really cannot separate those patients. We would like to analyze them. I can tell you that when we looked at hypoplastic arch repair versus coarctation repair, the incidence of mortality went up by about $1 \%$ for each group. That is, $1 \%$ mortality increase from coarctation repair to coarctation plus VSD, another $1 \%$ increase in mortality for hypoplastic arch repair, and then a $1 \%$ increase when VSD repair was added to hypoplastic arch repair, but I cannot comment on the quality of those data because we cannot specify how patients are assigned (by their various surgical groups) to each particular repair type. 
You asked about coarctation and whether it is a straightforward operation and the incidence of complications. It can be a straightforward operation. As you see, only about half the patients in the isolated group had complications. It can also be a very complex operation, with a high likelihood of complication, so I think it is important to recognize that. The length of stay for isolated coarctation was about 5 days as a median. It went up to about 11 days if there was a VSD and was about 9 days when coarctation existed with other lesions, so it can be a complex convalescence.

Last, you asked about the incidence of neonates versus other patients. It is interesting that you went back to your database. I always say the memory is a poor database and so we may remember that we are operating on a lot of neonates and infants, and forget that there are other patients that are getting operated on as well. The map is not the territory, meaning that our own individual experiences may not represent the overall totality of experience in the country, and that is a major benefit of the STS database. I think the numbers here are pretty good and I would suggest that what we are seeing is that about half the patients overall being operated on for coarctation are neonates, that this percentage of neonates is higher in the patients with more complex disease, and that the incidence of complications after coarctation repair is higher than we would initially remember. Thank you.

Dr Cohen. Thanks. One other quick comment. Thank you, by the way, for giving me the paper in advance and allowing me to review it, but one thing that was not clear to me from the paper and even from the presentation: I am assuming that you excluded hypoplastic left heart syndrome from group 3. You did say that you included single ventricles. It would be helpful, I think, both in the manuscript and in the discussion to clarify that.

Dr Ungerleider. They were excluded. Hypoplastic left heart syndrome is a separate disease. They get arch repairs, but they usually get something in addition.

Dr Tara Karamlou (San Francisco, Calif). Hi, Ross. Great paper. I just had one quick comment and a question.

In terms of looking at complications like recurrent laryngeal nerve injury, I think those things in this database are extremely problematic because we do not really know the denominator. I think we have to look at those data cautiously.

One of the things that struck me as curious was that there was a much increased incidence of nerve injury when you had a concomitant VSD as opposed to other complex lesions. Do you have a reason why you think that is the case or do you think it is just an anomaly of the data?

Dr Ungerleider. Clearly, the incidence of recurrent laryngeal nerve would probably be very different if it were looked for in all patients. All patients would have to receive some form of direct exam, and I think that the STS database information in this study only represents those patients who had aphonia or aspiration or a reason to be coded as recurrent laryngeal nerve injury. We can use these kinds of data to guide our questions for the future, and so if we really want to know more about why there seems to be a higher incidence of recurrent laryngeal nerve injury in certain subgroups of patients, we need to construct the database to help us answer those questions in the future. Thank you all. 